NBER WORKING PAPER SERIES

\title{
SPECIFICATION OF THE JOY OF GIVING: INSIGHTS FROM ALTRUISM
}

Andrew B. Abe 1

Mark Warshawsky

Working Paper No. 2154

\author{
NATIONAL BUREAU OF ECONOMIC RESEARCH \\ 1050 Massachusetts Avenue \\ Cambridge, MA 02138 \\ February 1987
}

\begin{abstract}
We thank Benjamin Friedman for helpful discussions and Greg Duffee and Marcy Trent for performing the numerical computations. Andrew Abel gratefully acknowledges financial support from the National Science Foundation. The views expressed in this paper are the authors' own and do not necessarily represent the opinions of the Board of Governors of the Federal Reserve System or its staff. The research reported here is part of the NBER's research program in Financial Markets and Monetary Economics. Any opinions expressed are those of the authors and not those of the National Bureau of Economic Research.
\end{abstract}


NBER Working Paper \#2154

\author{
Specification of the Joy of Giving: \\ Insights from Altruism
}

\begin{abstract}
$\underline{\text { ABSTRACT }}$
This paper analyzes the joy of giving bequest motive in which the utility obtained from leaving a bequest depends only on the size of the bequest. It exploits the fact that this formulation can be interpreted as a reduced form of an altruistic bequest motive to derive a relation between the value of the altruism parameter and the value of the foy of giving parameter. Using previous discussions of an a priori range of plausible values for the altruism parameter we then derive plausible restrictions on the joy of giving parameter. We demonstrate that this parameter may well be orders of magnitude larger than assumed in the existing literature.
\end{abstract}

Andrew B. Abel

Department of Finance The Wharton School

Steinberg Hall, Room 2319

University of Pennsylvania

Philadelphia, PA 19104
Mark Warshawsky Board of Governors Federal Reserve system Stop 90

Washington, DC 20551 
Bequest motives by individual consumers have important implications for the behavior of financial markets, the macroeconomic impacts of various fiscal policies and the intergenerational transmisssion of inequality in the distribution of wealth. There are at least four reasons for the existence of bequests which have been discussed in the recent literature: (1) bequests may be the unintentional by-product of precautionary savings and a stochastic date of death in the absence of an annuity market (Abel (1985)); (2) the prospect of bequests is used by parents to induce children to behave in certain ways desired by the parents (Bernheim, Shleifer, and Summers (1985)); (3) bequests may arise from intergenerational altruism, that is, consumers obtain utility from their heirs' utility as well as from their own consumption (Barro (1974) and Becker (1974)); and (4) bequests may arise from what may be termed the "joy of giving," that is, consumers leave bequests simply because they obtain utility directly from the bequest.

For some theoretical and empirical analyses of the issues affected by voluntary intergenerational transfers, the specification of the bequest motive is critical. For example, the validity of the Ricardian Equivalence Theorem depends crucially on an altruistic motive rather than a joy of giving motive. For many other purposes, however, the specification is not crucial. Many economists, including Yaari (1965), Hakansson (1969), Fischer (1973), and Abel (1986), have chosen the joy of giving model, either out of the belief that it captures the true reason for bequests, or more likely, because it is a convenient "reduced form" representation of altruistic preferences.

Furthermore, the joy of giving formulation has the practical advantage that it is more easily tractable. This tractability is especially important in simulation models, particularly those simulation models in which closed-form solutions are needed.

1.3 .1 
In most applications of the altruism model and the joy of giving model, the bequest motive is parameterized by a small number of parameters. Economic theory provides substantial guidance on the admissible, or at least plausible, values of the parameters in the simple formulations of the altruism model and these implications have been discussed by Drazen (1978), Burbidge (1983, 1984), Buiter and Carmichael (1984), and Weil (1984). However, there has evidently been no systematic discussion of the range of appropriate parameter values for simple formulations of the joy of giving model, despite the popularity of this formulation in empirical work.

The purpose of this paper is to explore the implications of economic theory for the appropriate range of parameter values for a popular specification of the joy of giving motive. The strategy pursued in this paper is to assume that the bequest is actually motivated by altruism and then to use the well-known restrictions on a simple formulation of the altruism model to derive restrictions on the parameter of a simple form of the joy of giving model. A striking result of this analysis is that the weight on the utility obtained directly from a bequest may be orders of magnitude larger than the values which appear in the literature (Eischer (1973), Blinder (1974)).

\section{A Model of Individual Behavior}

We consider consumers who live for L periods. For now, we suppose that the only source of disposable income is from past accumulation, that is, consumers receive only property income. This assumption will be relaxed in Section $\mathrm{V}$. We consider a family in which $\mathrm{N}$ periods elapse between the birth of successive generations. For simplicity, we assume that private intergenerational transfers from parent to child, that is, bequests, are made at the beginning of the child's life. Let $\omega^{j}$ be the wealth received by a generation $j$ consumer at the beginning of his life. Defining $c_{i}^{j}$, 
$i=1, \ldots . ., L$ as the consumption of a generation $j$ consumer when he is age $i$, and letting $R$ be the (gross) rate of return on the homogeneous wealth, we can write the lifetime budget constraint as a relation between the inheritance received by the generation $j$ consumer, $W^{j}$, and the bequest left by this consumer, $w^{j+1}$,

$$
W^{j}=\sum_{i=1}^{L} R^{-(i-1)} c_{i}^{j}+R^{-N} W^{j+1}
$$

We specify the utility function to be time separable in the consumer's own consumption and to display altruism. Letting $v^{j}$ be the present value of lifetime utility of the generation $j$ consumer we assume that the consumer has the following time-separable altruistic utility function

$$
v^{j}=\max \left\{\sum_{i=1}^{L} B^{i-1} u\left(c_{i}^{j}\right)+\beta^{N} \alpha V^{j+1}\right\}
$$

where $u^{\prime}>0, u^{\prime \prime}<0, B$ is discount factor reflecting time preference $(0<B<1)$ and $\alpha>0$ indicates the strength of the bequest motive. The maximization in (2) is subject to the constraint in (1) and to the transversality condition $\lim \mathrm{R}^{-\mathrm{Nj}_{W}} \mathrm{j} \geq 0$.

$$
j \rightarrow 0
$$

It has been noted by several authors (for example, Buiter and Carmichael (1984), and Weil (1985)) that in order for the maximization problem in (2) to be well-posed, we must restrict the weight on the heir's utility, $\beta^{\mathbb{N}} \alpha$, to lie between 0 and 1 . This restriction does not require a to be less than or equal to 1. To obtain some guidance on the appropriate range of values for $\alpha$, it is useful to define the term "full altruism." By "full altruism" we will mean that in every period in which both the generation $j$ consumer is alive and the generation $j+1$ consumer is alive, the optimal allocation of family consumption is for the parent and child to have equal consumption 
$\left(c_{N+i}^{j}=c_{i}^{j+1} i=1, \ldots, L-N\right)$. With the specification of the utility function in (2), full altruism corresponds to $\alpha=1$. If $\alpha<1$ then we will say that the utility function displays less than full altruism. ${ }^{1}$

If all generations in an infinitely-lived altruistic family are identical except for their dates of birth and the inheritances they receive at birth, then the utility of the generation $j$ consumer can be written as a function of the inheritance received at birth $V^{j}=V\left(W^{j}\right)$. Therefore equation (2) may be written as

$$
V\left(W^{j}\right)=\max \left\{\sum_{i=1}^{L} \beta^{i-1} u\left(c_{i}^{j}\right)+\beta^{N} \alpha V\left(W^{j+1}\right)\right\}
$$

Recalling that $\mathrm{w}^{j+1}$ is the bequest left by the generation $j$ consumer, equation (3) expresses the utility of the generation $j$ consumer as a function of his own consumption and the bequest he leaves. That is, equation ( 3 ) has the appearance of a "joy of giving" bequest motive. Strictly speaking, it is not a joy of giving bequest motive because the function $V($ ) cannot be specified independently; it is the solution to a functional equation. The strategy we will employ in this paper is to solve the functional equation implied by altruism and to use interpretable restrictions on altruistic preferences to derive restrictions on the parameters of the joy of giving specification. We begin by solving the maximization problem on the right-hand side of (3) subject to (1) and a given value of $w^{j}$. The first-order conditions can be expressed

$$
\begin{gathered}
u^{\prime}\left(c_{1}^{j}\right)=(R B)^{i-1} u^{\prime}\left(c_{i}^{j}\right), \quad i=2, \ldots ., L \\
u^{\prime}\left(c_{1}^{j}\right)=(R B)^{N} \alpha V^{\prime}\left(w^{j+1}\right)
\end{gathered}
$$

It is useful to obtain an expression for $V^{\prime}\left(W^{j+1}\right)$ in terms of the utility function $u()$. It follows immediately from the envelope theorem that

\section{3 .1}




$$
V^{\prime}\left(W^{j+1}\right)=u^{\prime}\left(c_{1}^{j+1}\right)
$$

Finally, use (4a, b) and (5) to obtain an expression relating consumption at a given age $i$ across successive generations

$$
u^{\prime}\left(c_{i}^{j}\right)=a(B R)^{N} u^{\prime}\left(c_{i}^{j+1}\right), \quad i=1, \ldots, L
$$

\section{Implications for the Steady State}

In this section we briefly analyze the life-cycle consumption pattern of an individual and the cross-sectional distribution of consumption in the steady state. To analyze the steady state, we assume that there are $\mathrm{N}$ types of families of consumers which are identical in all respects except for the dates at which births (and deaths) occur. We assume that there is an equal number of each type of family so that there is a constant number of consumers born each period.

A steady state is characterized by $c_{i}^{j}=c_{i}^{j+1}, i=1, \ldots, L$ and $w^{j}=w^{j+1}$. It follows from (6) that in the steady state

$$
\alpha(B R)^{N}=1
$$

Although $\alpha$ and $B$ are preference parameters and $R$ is assumed to be given to the individual, a more complete aggregate analysis could specify $R$ to be $a$ declining function of the aggregate capital stock. Such a formulation, which would allow for the endogenous adjustment of $R$ to the steady state value implied by ( 7 ), is beyond the scope of this paper. Our purpose here is simply to characterize the life-cycle and cross-sectional profiles of consumption.

We observe that under full altruism $(\alpha=1)$, condition (7) implies that $B R=1$. It is thus apparent from $(4 a)$ and (6) that both the life-cycle and cross-sectional profiles of consumption are flat. That is, in the steady state $c_{i}^{j}=\bar{c}$ for all $i$ and $j$ where $\bar{c}>0$ is constant. 
The steady state behavior of consumption is more interesting in the case of less than full altruism. In this case, with $\alpha<1$, condition (7) implies that $R_{B}>1$. With the rate of interest greater than the rate of time preference $\left(R>B^{-1}\right)$, (4a) implies that the path of optimal consumption over an individual's lifetime is monotonically increasing with age. Every consumer has the same lifetime path of consumption, and in a cross-section at a point in time old consumers have higher consumption than young consumers. Thus, in every period in which two successive generations in a family are alive, the parent's consumption exceeds the child's consumption, which is simply a reflection of less than full altruism.

\section{One-Period Non-Overlapping Generations}

Before deriving the utility function corresponding to the joy of giving motive in the general multi-period life case, it is useful to analyze the simple case with $L=N=1$ and to focus on the steady state. This simple case gives the flavor of the result that the weight on the joy of giving function may be quite large, and does so without a burdensome amount of algebra.

With $L=N=1$, we can write constraint (1) in the steady state as

$$
W=c+R^{-1} W
$$

where $c=c_{1}^{j}=c_{1}^{j+1}$ in the steady state. Evaluating the utility function (2) in the steady state yields

$$
V=u(c)+\alpha B V
$$

Now using (8) to substitute for $c$ in (9) and using (7) to replace $\alpha \beta$ by $R^{-1}$, we can rewrite ( 9 ) as

$$
V=\frac{R}{R-1} u\left(\frac{R-1}{R} W\right)
$$


Equation (10) expresses the steady state utility of an individual as a function of the inheritance he receives at birth. Much of the research using the joy of giving motive assumes that $u(c)$ is isoelastic

$$
u(c)=\frac{1}{1-\sigma} c^{1-\sigma} ; \sigma>0
$$

In addition, the joy of giving function is assumed to be isoelastic with the same elasticity as $u(c)$. This formulation of the joy of giving function is consistent with (10) as may be seen by combining (10) and (11) to obtain

$$
V=\left(\frac{R}{R-1}\right)^{\sigma} \cdot \frac{1}{1-\sigma} W^{1-\sigma}
$$

Observing that $\frac{R}{R-1}>1$, we see that $\left(\frac{R}{R-1}\right)^{\sigma}$, the weight on the joy of giving function, might be quite large. To determine how large this weight might be, we must go to the more general model which can accommodate more. realistic values for $L$ and $N$.

\section{The Multi-Period Model}

In this section, we allow both $\mathrm{N}$ and $\mathrm{L}$ to be large and we calculate the function $V^{j}=V\left(W^{j}\right)$ under the assumption that $u(c)$ has the isoelastic form in (11). We will verify that under isoelastic utility, the solution to the functional equation in (3) has the form

$$
V(W)=\phi \cdot \frac{1}{1-\sigma} W^{1-\sigma}
$$

where $\phi$ is the weight to be derived in this section.

Using the expressions for $u(c)$ and $V(W)$ in (11) and (13), respectively, we can rewrite the first-order conditions ( $4 a, b)$ as 


$$
\begin{gathered}
c_{i}^{j}=(R B)^{\frac{i-1}{\sigma}} c_{1}^{j} \quad i=2, \ldots ., L \\
W^{j+1}=\left[(R B)^{N_{\alpha \phi}}\right]^{\frac{1}{\sigma}} c_{1}^{j}
\end{gathered}
$$

Using (14a) to substitute for $c_{i}^{j}, i=2, \ldots, L$ and (14b) to substitute for $\mathrm{w}^{\mathrm{j}+1}$ in (1), we obtain

$$
W^{j}=\psi c_{1}^{j}
$$

where

$$
\begin{gathered}
\psi \equiv \Gamma+\left(\alpha \beta^{N_{R} N_{\phi}}\right)^{\frac{1}{\sigma}} R^{-N} \\
\Gamma \equiv \sum_{i=1}^{L}\left[R^{\frac{1}{\sigma}-1} \beta^{\frac{1}{\sigma}}\right]^{i-1}
\end{gathered}
$$

Next use $(14 a)$ and $(14 b)$ to substitute for $c_{i}^{j}, i=2, \ldots, L$ and $w^{j+1}$ in the functional equation (3). Using the specifications of $u(c)$ and $V(W)$ in (11) and (13), respectively, we obtain

$$
V\left(W^{j}\right)=\psi \cdot \frac{\left(c_{1}^{j}\right)^{1-\sigma}}{1-\sigma}
$$

Now use (15a) to express the right-hand side of (16) as a function of $\mathrm{W}^{\mathrm{j}}$ and use (13) to rewrite the left-hand side of (16) to obtain

$$
\phi \cdot{\frac{\left(W^{j}\right)}{1-\sigma}}^{1-\sigma}=\psi^{\sigma}{\frac{\left(W^{j}\right)}{1-\sigma}}^{1-\sigma}
$$

It follows from (17) that $\phi^{\frac{1}{\sigma}}=\psi$ so that using $(15 \mathrm{~b})$ we obtain

$$
\phi=\left|\frac{\Gamma}{1-\mathrm{R}^{-\mathrm{N}}\left(\alpha \beta^{\mathrm{N}} \mathrm{R}^{\mathrm{N}}\right)^{\frac{1}{\sigma}}}\right|^{\sigma}
$$


The expression for $\phi$ in (18) was derived without assuming that the steady state condition (7) holds and thus is not restricted to steady states. Note that in the steady state we obtain ${ }^{2}$

$$
\phi=\left[\frac{\Gamma}{1-R^{-N}}\right]^{\sigma} \quad \text { when } \alpha(\beta R)^{N}=1
$$

In order to make our findings more easily interpretable in terms of, for example, Fischer (1973), note that under isoelastic utility, the utility function in (3) can be written as

$$
V\left(W^{j}\right)=\left\{\sum_{i=1}^{L} B^{i-1}\left(c_{i}^{j}\right)^{1-\sigma}+\lambda\left(w^{j+1}\right)^{1-\sigma}\right\} /(1-\sigma)
$$

where

$$
\lambda \equiv \alpha \beta^{N}{ }_{\phi}
$$

We have defined $\lambda$ so that it is comparable to the bequest weight $\hat{b}_{t}$ in Fischer (1973). Substituting (18) into (20b) yields

$$
\lambda=R^{-N}\left|\frac{\Gamma}{\left(\alpha B_{R^{N}}\right)^{-\frac{1}{\sigma}}-R^{-N}}\right|^{\sigma}
$$

If we restrict our attention to the steady state, then (21) can be simplified using (7) to obtain

$$
\lambda=R^{-N}\left|\frac{\Gamma}{1-R^{-N}}\right|^{\sigma} \quad \text { if } \quad \alpha(B R)^{N}=1
$$

Table 1 presents the implied values of $\lambda$ and a corresponding to various rates of time preference and steady state interest rates. Looking across the last four columns of each row, it is clear that the weight $\lambda$ is an increasing 
function of the coefficient of relative risk aversion $\sigma$. The striking result in Table 1 is that even with a coefficient of relative risk aversion as low as 2 , the value of $\lambda$ can be orders of magnitude larger than the values assumed by previous authors. For example, Table 1 of Fischer (1973) indicates that for four sets of his simulations, Fischer used a rate of time preference of .04 (actually $B=.96$ ), a net interest rate of .06 , and a coefficient of relative risk aversion of 2.0. Although he uses a time-varying weight on the bequest motive, this weight is roughly equal to 1 (it always lies between .42 and 1.20). The first row of Table 1 indicates that for $\sigma=0.5$ a value of $\lambda$ around 1 is consistent with altruism but for $\sigma=2$, a value of $\lambda$ around 100 is required to be consistent with altruism in the steady state.

The calculations reported in Table 1 are limited to the steady state in which condition (7) implies a restriction on $\beta, R$ and $\alpha$. If we relax the assumption that we are in a steady state, then $\alpha$ can be specified independently of $B$ and $R$. We can use this extra degree of freedom on the parameters to answer the following question: given a time preference discount factor $\beta$, a gross interest rate $R$, and a bequest weight $\lambda$, what is the implied degree of altruism $\alpha$ ? Straightforward manipulation of (21) yields

$$
\alpha=(\beta R)^{-N}\left\{R^{-N}+\left(R^{N} \lambda\right)^{-\frac{1}{\sigma}} \Gamma\right\}^{-\sigma}
$$

It is clear from (23) that for given $R$ and $B$ there is a monotonically increasing relation between $\alpha$ and $\lambda$. However, this relation is nonlinear. In Table 2 we report values of $\alpha$ corresponding to $R=1.06, B^{-1}-1=.04$ and various values of $\sigma$ and $\lambda$. The last entry in Table 2 indicates that the implied degree of altruism in Fischer (1973) is quite small relative to full altruism for the case with $\sigma=2$. 


\section{Non-Property Income}

In previous sections we have assumed that the only source of disposable resources is wealth inherited at birth. In this section we assume that a generation $j$ consumer receives an exogenous deterministic income $y_{i}^{j}$ when he is age i.

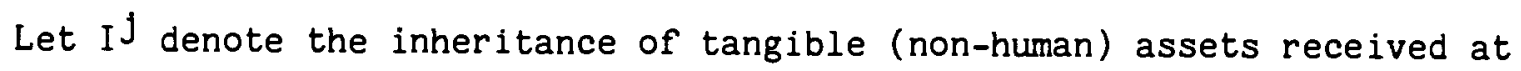
birth by the generation $j$ consumer and let $Y^{j}=\sum_{i=1}^{L} R^{-(i-1)} y_{i}^{j}$ denote the value of the human wealth of the generation $\mathrm{J}$ consumer. Now let $\mathrm{H}^{j}$ be the present value of the human wealth of the generation $j$ consumer and all of his descendents

$$
H^{j}=\sum_{k=0}^{\infty}\left(R^{-N}\right)^{k_{Y}}{ }^{j+k}
$$

Next, let $w^{j}$ now denote the total wealth, human plus non-human, of the generation $\mathrm{j}$ consumer and his descendents, as of the beginning of the generation $\mathrm{j}$ consumer's life,

$$
W^{J}=I^{j}+H^{j}
$$

Finally, let $B J$ denote the bequest left by a generation $j$ consumer so that $I^{j+1}=B^{j}$. Therefore, equation (25) implies that

$$
W^{j+1}=B^{j}+H^{j+1}
$$

The analysis of previous sections continues to apply if we now interpret $\mathrm{W}^{\mathrm{J}}$ to include human as well as non-human wealth. In particular, we can write the isoelastic altruistic utility function in (20a) as

$$
V\left(W^{j}\right)=\left\{\sum_{i=1}^{L} B^{i-1}\left(c_{i}^{j}\right)^{1-\sigma}+\lambda\left(B^{j}+H^{j+1}\right)^{1-\sigma}\right\} /(1-\sigma)
$$


Equation (27) expresses the utility of the generation $j$ consumer as a function of his own consumption $c_{i}^{j}, i=1, \ldots, L$ and the bequest he makes, $\mathrm{B}^{j}$. This equation is equivalent to a joy of giving formulation. Unlike the joy of giving functions in Abel (1986), Blinder (1974), Fischer (1973), Friedman and Warshawsky (1985), Hakansson (1969), and Richard (1975), however, it is not isoelastic, although the period utility function $u()$ is isoelastic. Treating the exogenous human wealth term $\mathrm{H}^{j}$ as a parameter, the joy of giving function is a member of the more general HARA class of utility functions.

In terms of consumer behavior, it is, of course, the marginal utility function rather than the utility function per se which is important. In the altruistic formulation in (27) the marginal utility of leaving a bequest is

$$
\frac{\partial V^{j}}{\partial B^{j}}=\lambda\left(W^{j+1}\right)^{-\sigma}
$$

Recalling that $B^{j}=I^{j+1}$ we may rewrite $(28)$ as

$$
\frac{\partial V^{j}}{\partial B^{j}}=\lambda\left(\frac{I^{j+1}}{W^{j+1}}\right)^{\sigma}\left(B^{j}\right)^{-\sigma}
$$

Now consider a joy of giving specification of the bequest motive. If, as is typical in the joy of giving framework, the bequest motive is specified to have the isoelastic form $\lambda^{*}\left(B^{j}\right)^{1-\sigma} /(1-\sigma)$, the marginal utility of a bequest would be

$$
\frac{\partial V^{j}}{\partial B^{j}}=\lambda^{*}\left(B^{j}\right)^{-\sigma}
$$

where $\lambda^{*}$ is the weight on the bequest motive. In order to calibrate $\lambda^{*}$ so 
that the calculated marginal utility in (30) would equal the marginal utility in (29), we would equate the right-hand sides of (29) and (30) to obtain

$$
\lambda^{*}=\lambda\left(\frac{I^{j+1}}{W^{j+1}}\right)^{\sigma}=R^{-N}\left|\frac{\Gamma\left(I^{j+1} / W^{j+1}\right)}{\left(\alpha \beta_{R^{N}}\right)^{-\frac{1}{\sigma}}-R^{-N}}\right|^{\sigma}
$$

The second equality in (31) follows from (21). Of course, the adjustment factor $\left(\frac{\mathrm{I}^{j+1}}{\mathrm{~W}^{j+1}}\right)^{\sigma}$ in (31) depends on the bequest $B^{j}$. However, since the goal of this adjustment is merely to choose an appropriate magnitude for $\lambda^{*}$ in empirical and simulation work, some rough proxies for $I^{j+1} / W^{j+1}$ may be used such as the population average ratio of inheritances to total wealth, or a particular family's (or group of families') historical average value of this ratio. At this level of analysis, all we can say is that $I^{j+1}<W^{j+1}$ so that $\lambda^{*}<\lambda$ where $\lambda$ is given by (20a). Put differently, the parameter $a$ of the altruistic bequest motive corresponding to a particular value of $\lambda^{*}$ is larger than the a corresponding to the same value of $\lambda$ in the model without human wealth. We can, using (31), calculate the value of a corresponding to a given value of $\lambda^{*}$ as

$$
\alpha=(B R)^{-N}\left\{R^{-N}+\left(I^{j+1} / W^{j+1}\right)\left(R^{N} \lambda^{*}\right)^{-\frac{1}{\sigma}} \Gamma\right\}^{-\sigma}
$$

Equation (32) can be used to interpret the bequest parameters derived by Friedman and Warshawsky (1985) in a joy of giving framework. Friedman and Warshawsky point out that the observed reluctance of most individuals in the United States to purchase individual life annuities, and the concomitant approximately flat age-wealth profiles of retired consumers, stand in sharp contradiction to the standard (no bequest motive) life-cycle model of 
consumption and saving behavior. Simulation of an extended model of lifecycle saving and portfolio behavior, allowing explicitly for uncertain lifetimes, Social Security, and empirically observed annuity prices, indicates that an intentional bequest motive must be present in order to explain the observed limited participation in annuity markets. Friedman and Warshawsky derive the minimum values for the bequest motive parameter which will eliminate purchases of individual annuities under various assumptions about the gross interest rate, $R$, the proportion of Social Security in the average retired individual's portfolio, $S$, the degree of risk aversion and the degree to which annuity prices exceed the actuarially fair prices. Their results, which are reproduced in the top panel of Table 3, might explain the apparent failure of most consumers to buy annuities as the consequence of apparently strong bequest motives.

An alternative measure of the strength of the bequest motive is the implied value of the altruism parameter $\alpha$. Since the expected present value of Social Security income is not bequeathable, Social Security wealth is appropriately treated as human, or non-property, wealth rather than as a tangible asset. Because of the presence of human wealth, we use equation (32) to calculate the altruism parameter. The bottom panel of Table 3 reports the calculated values of $\alpha$ using (32) with $N=30, L=60$, and $B=(1.01)^{-1}$. The assumed values of $R$ and the calculated values of $\alpha$ are reported in Table 3. For the ratio of tangible property wealth to total wealth, $I / W$, we use $1-S$, where $S$ is the share of Social Security wealth in total wealth reported in the top panel of Table 3. Finally, the values of $\lambda^{*}$ are taken from the top panel of Table 3. The picture which emerges from the bottom panel of Table 3 is quite different from that in the top panel. In all cases the degree of the implied altruism parameter is quite small. In assessing these small values of 
a it must be kept in mind that the Friedman and Warshawsky calculations produced a lower bound on the strength of the bequest motive. Additionally, the present value of human wealth of future generations has been ignored. The bequest motives may, therefore, be substantially larger than the implied lower bounds presented in Table 3. Nevertheless, the findings indicate that given the actual pricing of annuities, a weak altruistic bequest motive will be sufficient to eliminate the purchase of private annuities.

\section{Conclusions}

This paper analyzes the joy of giving bequest motive in which the utility obtained from leaving a bequest depends only on the size of the bequest. It exploits the fact that this formulation can be interpreted as a reduced form of an altruistic bequest motive to derive a relation between the value of the altruism parameter and the value of the joy of giving parameter. Using previous discussions of an a priori range of plausible values for the altruism parameter we then derive plausible restrictions on the joy of giving parameter. We demonstrate that this parameter may well be orders of magnitude larger than assumed in the existing literature.

Despite its analytic tractability, there has been some reluctance to use the joy of giving formulation even in analyses where only a generic bequest motive is necessary. This reluctance may owe to the difficulty of making reasonable assumptions about, and in empirical work and simulation models reasonable interpretations of, the joy of giving parameter. In removing this difficulty, this paper takes an important step in interpreting empirical work and simulation results which are directed at understanding actual economic phenomena related to bequests. 


\section{Footnotes}

'For more general specifications of the utility from one's own consumption, there may not exist any value of a for which the utility function displays full altruism.

2If consumption takes place in continuous time, then the functional equation (3) can be written as $V\left(W^{j}\right)=\delta_{0}^{L} u(c(z)) e^{-\delta z} d z+e^{-\delta N_{\alpha}} \cdot V\left(W^{j+1}\right)$. If $u($ ) has the isoelastic form in (11), then it can be shown that $V\left(W^{j}\right)=\phi \frac{1}{1-\sigma}\left(w^{j}\right)^{1-\sigma}$ where $\phi=\left[\delta_{0}^{L} \exp \left\{\left(\left(\frac{1}{\sigma}-1\right) r-\frac{\delta}{\sigma}\right) t\right\} d t /\right.$ $\left.\left(1-\alpha^{\frac{1}{\sigma}} \exp \left\{\left(\left(\frac{1}{\sigma}-1\right) r-\frac{\delta}{\sigma}\right) N\right\}\right)\right]^{\sigma}$. In the steady state $\alpha e^{(r-\delta) N}=1$ so that $\phi=\left[\delta_{0}^{L} \exp \left\{\left(\left(\frac{1}{\sigma}-1\right) r-\frac{\delta}{\sigma}\right) t\right\} d t /(1-\exp (-r N))\right]^{\sigma}$. 
Table 1

Weights on Joy of Giving Function and Implied Degree of Altruism

\begin{tabular}{|c|c|c|c|c|c|c|}
\hline$B^{-1}-1$ & $R$ & $\alpha$ & \multicolumn{3}{|c|}{$\lambda$} \\
\hline & & & $(\sigma=.5)$ & $(\sigma=1)$ & $(\sigma=2)$ & $(\sigma=4)$ \\
.04 & 1.06 & .56 & 1.14 & 4.96 & 100.99 & 43,076 \\
.04 & 1.04 & 1. & 1.80 & 10.49 & 356.76 & 412,807 \\
.02 & 1.06 & .32 & 2.01 & 7.47 & 142.29 & 58,940 \\
.02 & 1.04 & .56 & 2.86 & 15.80 & 524.71 & 600,160 \\
.02 & 1.02 & 1. & 4.91 & 43.70 & $3,459.06$ & $21,673,136$ \\
.01 & 1.06 & .23 & 2.91 & 9.57 & 172.13 & 69,611 \\
.01 & 1.04 & .42 & 3.93 & 20.24 & 649.94 & 732,042 \\
.01 & 1.02 & .74 & 6.38 & 55.96 & $4,398.76$ & $27,466,003$ \\
.01 & 1.01 & 1. & 9.84 & 130.53 & $22,964.63$ & $710,820,614$ \\
\hline
\end{tabular}

Source: Calculations based on equation (22) with $\mathrm{N}=30, \mathrm{~L}=60$. 
Table 2

The Implied Degree of Altruism $\alpha$

\begin{tabular}{|c|c|c|c|c|c|c|}
\hline & \multicolumn{3}{|c|}{$\lambda=.5$} & \multicolumn{2}{c|}{$\lambda=1.0$} \\
\hline & $\sigma=.5$ & $\sigma=1.0$ & $\sigma=2.0$ & $\sigma=0.5$ & $\sigma=1.0$ & $\sigma=2.0$ \\
\hline & .268 & .067 & .004 & .507 & .132 & .008 \\
\hline
\end{tabular}

$R=1.06$

$\beta=(1.04)^{-1}$

$\alpha$ is calculated from (23). 
Table 3

Estimates of Bequest Motive Parameter $\lambda^{*}$, from Friedman and Warshawsky (1985)

\begin{tabular}{|c|c|c|c|}
\hline & $S=.4$ & $S=.5$ & $S=.6$ \\
\hline$R=1.01$ & & & \\
$\sigma=2$ & 18 & 9 & 4 \\
$\sigma=3$ & 169 & 58 & 18 \\
$\sigma=4$ & 1488 & 343 & 74 \\
$R=1.04$ & & & \\
$\sigma=2$ & & & 3 \\
$\sigma=3$ & 10 & 56 & 7 \\
$\sigma=4$ & 419 & 24 & 22 \\
\hline
\end{tabular}

Implied Values of Altruism Parameter $\alpha$

\begin{tabular}{|l|c|c|c|}
\hline & $I / W=.6$ & $I / W=.5$ & $I / W=.4$ \\
\hline$R=1.01$ & & & \\
$\sigma=2$ & .025 & .019 & .014 \\
$\sigma=3$ & .007 & .005 & .003 \\
$\sigma=4$ & .002 & .001 & .001 \\
\hline$R=1.04$ & & & \\
$\sigma=2$ & .031 & .0023 & .005 \\
$\sigma=3$ & .005 & .009 & .002 \\
$\sigma=4$ & & .003 & \\
\hline
\end{tabular}

Source: Top Panel - Friedman and Warshawsky (1985), Table $9 ; \quad B=(1.01)^{-1}$ Bottom Panel - Equation (32) with $\beta=(1.01)^{-1}, \mathrm{~N}=30, \mathrm{~L}=60$ $\lambda$ from Top Panel with $I / W=1-S$. 


\section{References}

Abel, Andrew B., "Precautionary Saving and Accidental Bequests," American Economic Review, September 1985, 75, 777-791.

, "Capital Accumulation and Uncertain Lifetimes with Adverse Selection," Econometrica, September 1986, 54, 5, 1079-1097.

Barro, Robert J., "Are Government Bonds Net Wealth?" Journal of Political Economy, November/December 1974, 82, 1095-1117.

Becker, Gary S., "A Theory of Social Interactions," Journal of Political Economy, November/December 1974, 82, 1063-1093.

Blinder, Alan S., Toward an Economic Theory of Income Distribution, Cambridge Mass.: MIT Press, 1974.

Bernheim, B. Douglas, Andrei Shleifer and Lawrence Summers, "The Strategic Bequest Motive," Journal of Political Economy, December 1985, 93, 10451076.

Buiter, Willem and Carmichael, Jeffrey, "Government Debt: Comment," American Economic Review, September 1984, 74, 762-765.

Burbidge, John B., "Government Debt in an Overlapping-Generations Model with Bequests and Gifts," American Economic Review, March 1983, 73, 222-227.

1984, "Government

Drazen, Allan, "Government Debt, Human Capital and Bequests in a Life Cycle Model," Journal of Political Economy, June 1978, 86, 505-516.

Fischer, Stanley, "A Life Cycle Model of Life Insurance Purchases," International Economic Review, February 1973, 14, 132-152.

Friedman, Benjamin M. and Mark Warshawsky, "Annuity Prices and Saving Behavior in the United States," National Bureau of Economic Research Working Paper No. 1683, August 1985; to appear in Zvi Bodie, John Shoven and David Wise (eds.), Issues in Pension Economics, University of Chicago Press, for thcoming.

Hakansson, Nils H., "Optimal Consumption and Investment Strategies Under Risk, An Uncertain Lifetime, and Insurance," International Economic Review, October $1969,10,443-466$.

Richard, Scott E., "Optimal Consumption, Portfolio and Life Insurance Rules for an Uncertain Lived Individual in a Continuous Time Model," Journal of Einancial Economics, 2, 1975, 187-203.

Weil, Philippe, "'Love Thy Children': Reflections on the Barro Debt Neutrality Theorem," mimeo, Harvard University, October 1984. 
Yaari, Menahem E., "Uncertain Lifetimes, Life Insurance, and the Theory of the Consumer," Review of Economic Studies, April 1965, 32, 137-150. 